\title{
Private Health Insurance in Britain and the National Health Service
}

\author{
by Nick Bosanquet*
}

The events of the 1980's have led in Britain to some increase in coverage of private health care: but this has not gone far enough to call in question the central role of the National Health Service. Private health care remains a distinct and different system with its own special mix of services: it does not attempt to provide the range of comprehensive care for most of the population at which the NHS aims. The new feature of the 1980's has been that the private sector has had to face its own internal crisis of management and cost control.

At the end of the 1970's it appeared that Britain might well be moving towards a mixed system of health care in which private insurers would play a much larger role. A U.K. Government Minister forecast at that time that the balance would settle at 75: 25: however in practice the balance has settled at 90:10. The growth on the demand side was certainly rapid from $1979-81$ with coverage increasing by $25.9 \%$ in 1980 : but by 1982 that rate of growth had fallen to $3-4 \%$ where it has remained since. The rise in demand increased coverage from 2.2 million people in 1977 to $4.9 \mathrm{~m}$ in 1983. (Maynard 1986) The traditional market for health insurance had been among corporate subscribers: growth in demand was partly for this traditional type of coverage but also for increased coverage among individuals and among dependents. The increased demand for coverage led in the early 1980's to an increased demand for services. It was believed in the industry that individuals when first covered tended to bring forward demand which had not been expressed under the National Health Service.

The industry increased its prices in face of this rise in demand for services. Subscription rates rose for one major company by $25 \%$ in $1981,22 \%$ in 1982 and by $14-18 \%$ since 1983 . However at the endof 1986 BUPA, the largest non-profit group was able to contain its biannual rise in subscriptions to $3 \%$, signalling that the problem may be under control. (Fiancial Times, 1987). As well as increasing prices the industry increased supply, with a rise in the number of beds in private hospitals. Private health care can now be given either in "pay beds" which are attached to NHS hospitals and which use services provided by these hospitals. There has been some expansion in the number of such beds from 2402 in 1980 to 3250 in 1983 but the occupancy rate fell from $63 \%$ in the late 1970 's to $55 \%$ in 1981 . Private

\footnotetext{
* Senior Research Fellow Centre for Health Economics, University of York: text presented at the General Assembly of the Geneva Association, Berlin, June 16, 1987.
} 
health care can also be given independently of the NHS, in private hospitals. In 1983 there were about 175 private hospitals in England with operating theatres, and these hospitals had 7571 beds of which nearly $53 \%$ are in London and the South East. The number of beds has increased further since and there are now some signs of over-capacity. The main increase in supply came not from traditional non-profit organizations but from American owned for-profit organizations. However the expansion that took place was much less than had been anticipated in 1980. The pattern of services remained concentrated on elective surgery, with growth in orthopaedics supplementing the traditional areas of work in gynaecology and general surgery. Expenditure is largely on room charges $(46 \%)$ with surgeons and anaesthetists fees accounting for over a quarter of expenditure $(25.5 \%)$, out-patient physician fees $5 \%$ and $7 \%$ for miscellaneous items. (Maynard 1986) The structure of costs is different from that found in the NHS where medical costs are about $9 \%$ of costs per day. Costs of medical services are clearly much more important to the private sector.

By the end of the period of rapid expansion in 1983, the range of coverage given by private insurers was as follows.

Table 1: Private Health Care Coverage (by numbers covered by insurer 1983)

Non profit

British United Provident Association (BUPA)

3015

62.1

Private Patients Plan (PPP)

Western Provident Association (WPA)

Bristol Contributory Welfare Association

Exeter Hospital Aid Society

Civil Service Medical Aid Association

Provincial Hospital Services Association

Private Patients Anglia

Total non profit

For profit

Allied Medical Insurance (AMI)

Crusader

Mutual of Omaha

Iron Trades

Crown

Orion / MT Medex

Total for profit

Overall Total

Source: BUPA (1984) 
The dominant Company in this market place in BUPA whose market share has fallen in recent years but is still substantial $(62 \%)$. The second largest non-profit making organization in this market is PPP with nearly $20 \%$ of the market. Since 1983 growth in coverage has been concentrated on certain special groups. Thus by 1986 Western Provident had raised the numbers covered from 350,000 in 1983 to 480,000 . (Financial Times 1987). Most of its new business has come from its Company Supercover scheme which is especially geared to small businesses of 5 to 40 employees. There are now more than 6,000 such groups in WPA's scheme. Many of them are new to the private sector and their decision may well reflect the fact that small companies cannot afford to lose key members of staff. As the pattern of employment shifts towards small businesses there is likely to be further growth in this demand. The industry is in general more competitive and the co-operation which took place between non-profit organizations is not now so common.

Table 2 gives information on the scale of benefits paid at the end of the period of expansion. Again the non-profit organizations dominate, with BUPA paying out nearly $60 \%$ of total benefits. The total outlay for the private insurance sector was about $£ 319 \mathrm{~m}$ in 1983.

Table 2: Private Health Care Benefits Paid by Insurer (1983)

\begin{tabular}{lrr}
\hline & $\begin{array}{r}\text { Benefits } \\
\text { paid (£000) }\end{array}$ & $\begin{array}{r}\text { Share } \\
(\%)\end{array}$ \\
\hline Non profit & & \\
British United Provident Association (BUPA) & 191,261 & 59.9 \\
Private Patients Plan (PPP) & 79,637 & 25.0 \\
Western Provident Association (WPA) & 20,495 & 6.4 \\
Bristol Contributory Welfare Association & 4,618 & 1.4 \\
Exeter Hospital Aid Society & 604 & 0.2 \\
Civil Service Medical Aid Association & 1,489 & 0.5 \\
Provincial Hospital Services Association & 270 & 0.1 \\
Private Patients Anglia & 25 & - \\
& 298,399 & 93.5 \\
Total non profit & & \\
For profit & 2,000 & 0.6 \\
Allied Medical Insurance (AMI) & 7,700 & 2.4 \\
Crusader & 3,400 & 1.1 \\
Mutual of Omaha & 2,600 & 0.8 \\
Iron Trades & 6 & - \\
Crown & 6,6 & 1.6 \\
Orion / MT Medex & 5,100 & 6.5 \\
Total for profit & 20,806 & 100.0 \\
Overall Total & 319,205 &
\end{tabular}

Source: BUPA (1984) 
In addition to the insurance funds there is self-finance and the most recent available data for 1981 indicates that this accounted for about $31 \%$ of total expenditure. Thus gross expenditure on private health care was about $£ 460 \mathrm{~m}$ in 1983 . Such figures have to be compared with total expenditure on the NHS which amounted to $£ 13 \mathrm{Bn}$ in 1983-84. The modest growth of $3-4 \%$ in the number of subscribers covered since 1983 will not have changed the relative size of the two sectors.

As well as private health care financed by insurance there are also certain types of private care which are financed by direct payment. The largest single private contribution in services is to abortion where private and voluntary services account for $28 \%$ of cases. Most of these abortions would be paid for directly. The role of the private sector has been important since the late 1960's: this came about because of the reluctance of some gynaecologists within the NHS to provide the service. There is also a well established private role in occupational health services covering both advice to employers on hazards at work and screening and treatment of individuals. The NHS has never been able to provide a service throughout industry in occupational health and it is in this area that the private sector is most clearly complementary to the NHS. Large organizations such as the Ford Motor Company, the Post Office and British Rail employ their own medical and nursing staff: other smaller companies use outside services provided by BUPA and others. There has been some growth in demand for screening of individuals.

The largest area of growth in private health care - and the least widely predicted - has been in long-stay places in nursing homes for the elderly. Here the number of places in nursing homes and homes for the elderly have doubled from 55,000 in 1979 to 110,000 in 1986 and the private sector now accounts for about $40 \%$ of the places available in such are. In a time of rapid expansion in the number of people over 75 , the private sector accounts for most of the increase in places. Most residents finance their stays through a mixture of special allowances which can be claimed by individuals under the social security system and private savings. The role of health insurance in this sector has been small and in fact benefit packages have been revised to exclude long stay care. The expansion of nursing homes has been financed through banks and the private capital market.

The main contribution of insurance financed health care lies in surgical treatment. (Williams et al 1985). About $13 \%$ of all domestic in-patient elective surgery in England and Wales was carried out in the private sector in 1981 . This proportion rose to $26 \%$ for certain operations and $20 \%$ of the total in-patient case load for elective surgery in London and the South East. There has been some expansion from the traditional areas of cold surgery into more complex surgery and into specialist treatments such as those for infertility. It is frequently denied that the growth of the private sector has come about because of dissatisfaction with waiting times for certain types of operation in the NHS: however the private sector would appear to do most work where the NHS is least able to provide an immediate service and to do least in such areas as emergency care, maternity care, and primary care where the NHS service is readily available. Convenience in terms of choice of time of treatment and immediate access to treatment influence the decision to take out private health insurance (Propper 1987). But some newer entrants to the market are offering types of service which put the accent more on preventive and on primary care and which are very different from the types of care provided in the past. One of these new entrants is Health 
First, the British arm of one of the largest insurance companies in the United States Mutual of Omaha. This was launched in 1986 with the aim of achieving a coverage of 1 million by 1990: by the beginning of 1987 it was achieving a coverage of 140,000 . It has concentrated on the company market and on the demand from the self-employed. It has been involved in some innovations such as Medical Express, the private walk-in accident and emergency service near Oxford Circus. The main strategy of this new entrant is to provide specific types of health care rather than comprehensive coverage. The demand is most likely to be in those types of care where the NHS is weakest. For the future the industry expects some continued expansion of coverage at $3-4 \%$ a year: but growth could be faster if it succeeds in breaking away from its traditional markets.

The record since 1979 has to be seen against a background of some early changes which provided a favourable environment for the growth of the private sector. In 1980 the contracts of consultants in the NHS were altered so that there were much greater incentives to private practice. Any consultant could earn up to $10 \%$ of his full time salary through private practice and the reward for full time work in the NHS was reduced. The effect was to increase the supply of scarce medical time available to the private sector. More recently the government made health insurance premia tax deductible for those earning less than $£ 8,500$ a year whose employers enrolled them in private schemes: but the limit has not been raised and the restricitve enrolment conditions remain. The government has done little recently to subsidize or stimulate demand: nor has there been much cooperation on the supply side. Apart from the example of a lithotripter - which uses shock waves to shatter kidney stones - which was bought by BUPA and installed at St. Thomas's Hospital where it is operated by NHS staff there has been very little technical cooperation. The stimulus given by government action to the growth of the private sector in 1979-80 has not been repeated and recent proposals for the extension of tax relief for private insurance premia have been given little support.

The development of private health insurance since the peak of the early 1980's has been constrained by a series of changes which have affected the NHS. The political climate has some importance with the NHS retaining a degree of political support which has made for political caution the principle of a service free to all at the point of consumption still commands support and as long as such a service exists its presence is likely to cramp the growth of services for which the patient has to pay. However this constraint is nothing new and has been there since the beginning of the NHS. The new constraints arise from the ways in which the issues of "efficiency" and "effectiveness" have developed in Britain in the 1980's (Maynard and Bosanquet 1986). The NHS has been under pressure to meet rising public expectations and changing patterns of need. For decision-making at the centre rules have been developed to set the minimum requirement for funding or services in relation to changing need, and changing technology. Need is measured in terms of the extra requirement for health care implied by changes in demography. Thus people over 75 use eight times more health care than younger adults: if numbers over 75 increase by 70,000 a year as has been the case over the last few years, this is taken to require about $1 \%$ a year in extra health spending at constant prices. The allowance for extra technology is put more crudely at $0.5 \%$ a year. In addition to the pressures for extra spending from demography and technology there are policy aims in a number of different areas. One of these is community care 
where governments are committed to developing alternatives to large institutions for mentally ill and for mentally handicapped people. There are aims in prevention in terms of improved screening for cervical cancer and breast cancer. There are resource consequences from providing care for people suffering from AIDS. All these requirements together are estimated by a study carried out at the Centre for Health Economics, to point to a minimum requirement of $2 \%$ annual increase in spending at constant prices (Maynard and Bosanquet 1986). Yet the rate of increase in revenue resources available to the hospital and community health services has been below this at about $1 \%$ a year at most since 1980 . Thus NHS policymakers have had to make limited resources stretch over a growing number of policy commitments. This has led to a sustained effort to raise throughput in terms of the number of cases treated. The numbers treated by the hospital services have been rising by $2.5 \%$ a year since 1982, faster than the relevant growth rate of funding at $1 \%$. Thus unit costs have fallen in the acute hospital sector. At the same time policy-makers have changed the process of management by introducing general managers with short-term contracts and executive powers to improve the services. The U.K. has not had to face the problem of cost inflation within general hospitals and policy-makers have had some success in raising "efficiency". There has been little pressure to expand private or insurance based care on the grounds that it was more efficient. International evidence on health systems is usually taken in the U.K. to mean that insurance based systems are subject to cost inflation and to third party effects which make for difficulty in achieving efficiency. This international evidence has further weakened the incentive to bring about a shift away from the NHS towards insurance based care.

The NHS has also come to face new choices about effectiveness about how to use limited resources in order to maximize benefits to health. These present themselves in terms of choices between prevention and direct treatment. Thus incentives to reduce smoking are likely to have much higher benefits in terms of reducing smoking related diseases than programmes to treat people who are actually suffering from heart disease and lung cancer. The new choices are also about the timing of treatment with screening programmes aimed at ensuring early detection and screening of disease. Thus the NHS is investing in improving the programme for screening for cancer of the cervix and it is starting new programmes for screening for cancer of the breast. The incidence of these and other diseases is higher among social groups where there is least likely to be demand for private insurance, and the effectiveness of screening depends on comprehensive coverage of the population at risk. Changes in information technology are making it easier to develop the recall systems required for this type of population based programme. New screening programmes are also being developed for the early detection of heart disease and again these depend on regular contact with whole populations in primary care.

Ther are also new choices about effectiveness within the acute hospital service. New methods are being developed for measuring the benefits from alternative uses of scarce resources. Some studies use years of survival brought about by different forms of treatment. Others look at the costs and benefits of different forms of treatment in terms of chance in quality of life or quality adjusted life years. (QALYS). (Williams 1985). QALY data can be used to show how certain treatments such as coronary artery bypass grafting and hip replacement have low costs and high benefits compared with others. Thus a QALY from hip replacement costs about $£ 750$ but that from dialysis as much as $£ 14,000$. Such evidence 
can help to show which programmes should be expanded at the margin. It can also help to guide choices of programme which are partial substitutes. (Gudex, 1987). Thus kidney transplants are better value in terms of quality of life gained than haemodialysis. There will be further work to improve the measurement of quality and to extend the use of existing and new and better measures to a broad range of procedures. Such data are likely to be used more as one guide to the allocation of marginal resources. Given that society could do more in health care than can be afforded from finite resources, rationing is inevitable and the problem is how to ensure that QALYS are maximized from limited budgets.

In the NHS the central problem is that of making effective use of limited resources rather than of containing total expenditure. Central government sets a firm budget constraint and the range and availability of services then depends on the decisions taken by health authorities and by health professionals. The supply system shows some bias towards "glamour" medicine but this is weaker than in most systems because of the policy of rationing the number of centres which can carry out advanced treatments ("regional specialties") and also because of the power of the nursing profession. The commitment of professionals to care helps to maintain a high public reputation for the service and reduce the impact of the economic difficulties on the services day to day for individual patients. In this system the problem is to ration out scarce resources to meet needs. The main initiatives have been towards raising activity levels and towards greater centralization. The central theme is that of gaining more value for money, although this is mainly seen in terms of efficiency rather than effectiveness. The introduction of general management has been the single most important initiative. There has also been a movement towards the setting of more detailed targets - for example the numbers of different types of operation to be achieved by 1990 - and towards putting in place the bureaucratic and statistical systems required for monitoring the targets "performance indicators". The aim has been to achieve rising activity levels in response to pressure from public and patient opinion concerned about the level of funding, and the length of waiting times. As well as general management there have been some complementary initiatives to finance investment projects designed to reduce waiting times for surgical treatment. Thus the central problem in the British system has been one of service levels which are perceived to be inadequate rather than of cost inflation in hospital care. In fact real expenditure on hospital services since 1979 has risen less fast than real expenditure on the family doctor service and on drugs (Maynard and Bosanquet 1986). For the future the focus is likely to shift away from questions of efficiency to those of measuring real benfits to patients. The activity levels of the acute services may have risen but there is little mechanism of choice between low and high benefit treatments within the acute sector: nor is there any system for choosing between the benefits of programmes in preventive and acute care. Thus the rise in activity levels will not resolve the choices which present themselves in the British care not just because of the general fact of scarcity but because of the particular acute form of it which from arises the budget constraint set by central government.

The developments with the NHS in the 1980's may well mean that in the future private insurance may come to play a role which is complementary rather than competitive. The agenda was once headed by the large question of whether private insurance could replace the NHS in whole or part. The events of the 1980's have resolved that question at least for a time: the comprehensive health service aiming to provide effective care free at the point 
of consumption will continue: however this aim will always be constrained by the limits on the resources available, and the NHS may well have problems in providing new services. Private insurance may well be able to develop specialized services and market niches which will allow the industry to raise coverage from 4.5 to $6.0 \mathrm{~m}$ people by the early 1990 's.

\section{REFERENCES}

FINANCIAL TIMES (1987) Private Health Care Financial Times Survey Friday January 23, p.12-20.

GUDEX C. (1986) QALY'S and their Use by the Health Services. CHE Discussion Paper No. 20, University of York.

MAYNARD A. (1986) Public and Private Sector Interactions: An Economic Perspective. Social Science and Medicine Vol. 22, No. 11, p 1161-1166.

MAYNARD A, and BOSANQUET N. Public Expenditure on the NHS Recent Trends and Future Problems IHSM London, 1986.

PROPER C. (1987) An Econometric Estimation of the Demand for Private Health Insurance in the UK CHE Discussion Paper No. 24, University of York.

WILliAMS, A. (1985). Economics of Coronary Artery Bypass Grafting British Medical Journal 3 August 1985, 291, pp. 326-329.

WILLIAMS, B.T., NICHOLL J.P., THOMAS K.J., KNOWELDEN J., (1985), "Contribution of the Private Sector to Elective Surgery in England and Wales”. The Lancet, July 14, pp. 89-92. 